\title{
Coastal resilience potential as an indicator of social and morphological vulnerability to beach management
}

\author{
Francesco Bianco $^{\text {a,b, }}{ }^{*}$, Salvador García-Ayllón ${ }^{c}$ \\ ${ }^{a}$ Department of Earth Sciences, University of Florence, Via La Pira, 4-50121, Firenze, Italy \\ ${ }^{\mathrm{b}}$ Centre of Geo Technologies, Department of Earth and Polar Sciences, University of Siena, Via Vetri Vecchi 34, 52027, San Giovanni Valdarno, Arezzo, Italy \\ ${ }^{\mathrm{c}}$ Department of Civil Engineering, Technical University of Cartagena, Paseo Alfonso XIII, 52, 30203, Cartagena, Spain
}

\section{A R T I C L E I N F O}

\section{Keywords:}

Coastal management

Coastal erosion

Social justice

Coastal resilience

Diagnostic indicators of territorial change Italian coast

\begin{abstract}
A B S T R A C T
Indicator-oriented approaches embrace several aspects of coastal erosion vulnerability assessments. Nonetheless, coastal erosion is mostly increasing because of both the lack of univocal and resolutive practices on coastal management and increasing human pressure on coastal systems. This article proposes the implementation of an Index of Social and Morphological Vulnerability (ISMV) to show how the cost of services and morphological trends can affect the distribution of benefits, produce coastal narrowing, and consequently the resilience potential of coasts. This innovative indicator framework was carried out for the Mediterranean area of San Vincenzo in Italy. The analysis highlights that administrative actions can be crucial to support or to impoverish the resilience potential. Areas of relative regeneration capacity were distinguished as high (4.11), moderate (0.37), and low (0.33). They could be enhanced just by planning resolutive beach management at a local scale. In this context, some resolutive actions are proposed in the framework of an aggregate multi-index approach that connect with the main Intervention Concerning the Erosion Causes (ICEC) strategies. The results obtained support the definition of the ISMV as an adequate policy tool to implement modifications in the maritime domain concession system aimed at sustainability and social justice.
\end{abstract}

\section{Introduction}

Vulnerability assessment procedures seek to achieve an understanding of coastal erosion mechanisms, to define the exposed socioeconomic values, and to plan options to face this issue. These parameters are linked by a coevolutionary relationship (Sterr et al., 2000) that was widely investigated through the computing of indices. Such indices were used to produce consistent and exhaustive future scenarios, even if successful strategies were rarely proposed or adopted. In fact, the vast majority of coasts of our planet are exposed to increasing urban pressure. Two examples are the coasts of Europe that are still affected by incipient erosive patterns mainly due to human pressure (EEA, 2018, 2010; IPCC, 2007), and China's coastline which, at the present time, hosts almost 700 million people. This situation has already generated high levels of urban pressure on ecosystems, and such pressure is expected to increase sharply due to both demographic spreading as well as the rise in sea level (Sajjad et al., 2018).

Management actions taken by administrations very infrequently follow the prescriptions and results of the assessments. The decision- making process in this field must encompass bio-geophysical, economic, institutional and socio-cultural factors (Cooper and McKenna, 2008; Rangel-Buitrago et al., 2018; Sterr et al., 2000; Williams et al., 2018) to guarantee the sustainability of development plans and also the appropriate distribution of derived benefits. Particularly, sedimentary stock can be strongly affected by human-induced phenomena. They involve shifting erosive patterns, coastal squeezing, and can even conceal natural trends during the assessment phases (Doody, 1992, 2004; Pontee, 2013; Pranzini, 1989; Anfuso et al., 2013; Bianco et al., 2020). These feedbacks directly affect the sediment availability on the active beach. Sedimentary stock provides space for ecosystems to develop, as well as for the building of services and for human benefit. For these reasons, sedimentary stock represents the most important component of the coastal system to preserve in order to maintain the resilience potential of coasts (Bhamra et al., 2011; Coastal and Environmental Research Committee and Southeastern Universities Research Association, 2015; García-Ayllón, 2017; Klein et al., 2011; 1999; 1998; Raymond et al., 2017).

On the other hand, benefit distribution must consider the citizens,

\footnotetext{
* Corresponding author. Department of Earth Sciences, University of Florence, Via La Pira, 4-50121, Firenze, Italy.

E-mail address: francesco.bianco@unifi.it (F. Bianco).
} 
tourists, and stakeholders that are mainly concentrated in large coastal cities (Martínez et al., 2007). In this field, high levels of human pressure are now being detected in several Mediterranean coastal areas, such as the South of Italy and Spain (EEA, 2010), even if the current strict European environmental regulations have meant that no relevant increasing trend has been registered since the decade 1990-2000 in developed countries. This trend mostly affects sandy beaches, which globally host the largest part of the concentration of people, who locate to climatically and economically favorable areas of Europe (Barragán and de Andrés, 2015; Brown et al., 2009; Luijendijk et al., 2018; Martínez et al., 2007; Pranzini, 2018; Seto et al., 2011).

In this context, an Index of Social and Morphological Vulnerability (ISMV) is proposed as an innovative and mixed approach to calculate vulnerability assessment from a comprehensive point of view. This indicator can detail the level of vulnerability of a coastal site, considering phenomena that reduce the space for ecosystems, and limit the citizens' right to interact with coastal ecosystem services. It enhances previous studies that considered the social importance of public decisions on the beaches, as well as the potential for regeneration of the coastal system (Cooper and McKenna, 2008; Cutter et al, 2003, 2009; De Girolamo et al., 2006; Garcia Ayllon, 2018a,b). This index is proposed to express the resilience potential of the area. It involves morphological trends, economic trends of the prices, and elements of the system that directly affect the sedimentary stock, since it represents the space necessary to support resilience (Bhamra et al., 2011; Bridges et al., 2015; Klein et al, 1998, 2011; Salman et al., 2004). The use of GIS territorial change indicators enables each component to be investigated, and to observe the feedbacks that they release. This will provide crucial indications on the processes that costal managers should support or restrict. The method consists of a mixed multi-index approach to set out the strategies for management solutions; some of which, such as cause-effect analysis or Concerning Erosion Causes (ICEC) strategies (Pereira et al., 2018; Rangel-Buitrago et al., 2018; Williams et al., 2018), implicate adaptative designs, the use of the ecosystem, planned retreatment of the structures, their protection or even their sacrifice. ICEC will include the vulnerability assessment, and the integrating of adaptative plans at a normative level. The latter represents the greatest difficulty found by previous studies in the field in different countries, where, even if evolved and extended legislative systems exist, they mostly fail at a regional level (McKenna and Cooper, 2006; Neal et al., 2018).

The Italian Mediterranean area of San Vincenzo was chosen for verifying the usefulness of the ISMV index as it is representative of a coastal urbanized site settled on a sandy beach. Geomorphological assessment at this location has already shown that morphological trends depend heavily on artificial replenishment inputs. It reflects small period management plans that during the last 60 years were focused on the harbor building phases. Nourishments and hard defenses were carried out to stabilize the shoreline and protect the urban center, which spread and notably restricted the coastal zone during that period. These solutions were very frequent on the Italian coast as well as in other parts of Europe (Pranzini et al., 2015). However, these policies failed to stop the incipient erosive patterns that have characterized the last 60 years in the whole country, which today registers a total loss of $91.9 \mathrm{~km}^{2}$ of sandy beaches and a length of $1534.4 \mathrm{~km}$ (Ministero dell'Ambiente e della Tutela del Territorio e del Mare, 2017). Moreover, the geomorphological settings in Italy differ greatly from one region to another, and even between provinces within the same region, highlighting several management issues, different economic vocations, and a very fragmented normative framework.

\section{Area of study and methodology}

\subsection{Area of study}

San Vincenzo is a municipality located on the north western Italian coast of the Mediterranean area. It consists of a coastal stripe $13 \mathrm{~km}$ long, extending NW-SE in the Livorno Province of the Region of Tuscany (Fig. 1). The whole length of the coastal stripe contains sandy beaches which are only interrupted by the tourist harbor, which stands out as the most urbanized portion of the site (a detailed $\mathrm{Kmz}$ file of the area of study is available as supplementary GIS resource). Tourism represents the main industry of the municipality and has attracted an average of more than one million people per year in the last 13 years (Regione Toscana and ISTAT, 2019). Its population was 6910 in 2015 (Comune di San Vincenzo, 2016) concentrated in $33.14 \mathrm{Km}^{2}$, while a total of 81 maritime concessions for economic activities are irregularly distributed therein. $^{1}$

The concessions have been issued by different authorities to regulate the use of the beach. Only 35 of these concessions are businesses and are managed by the Local Municipal Authority; our assessment considers those ones. Although the sedimentary stock should represent the whole area within a coastal zone delimited as $200 \mathrm{~m}$ from the shoreline (EEA, 2010), at San Vincenzo this area is restricted by the anthropic structures. Hence, where there is less than $200 \mathrm{~m}$ it will be considered as the zone between the closure depth and the hard limit landward.

This coastal area can be divided into three subareas: the first to the north of the marina, the second to the south of the port infrastructure, and the third further south consisting of a regional park. The only coastal area not affected by urbanization processes is the latter one, where the Natural Park inland preserved that area from urbanization. In the other two zones the coastal area is permanently occupied by buildings and infrastructures (such as a mass road and railway) that strongly reduce it. These features will be considered for the calculation of the ISMV since they directly interact with the coastal zone, although at this scale of assessment they could not be considered in the management. Solutions will regard the sedimentary stock on which the active beach is over imposed physically and administratively.

With respect to the hydrodynamics, the area was isolated from the rest of the sedimentary cell to which it belongs, named Punta LillatroTorre Nuova (Mazzanti et al., 1980), by several hard structures on the northern side. Within San Vincenzo's Coastal Unit, longshore currents take two directions: N-S in the northern part, and $\mathrm{S}-\mathrm{N}$ in the southern, meeting at a convergence point in the middle of the Unit. The harbor represents a pass towards the offshore for the longshore currents flowing $\mathrm{N}-\mathrm{S}$. A further morphologic structure considered in the morphodynamic patterns is the submerged canyon at the southernmost part of the Unit. Considering these elements, the coastal stripe was first divided into three Sub-Units, (A, B, and C), and then into sectors comprising both homogenic territory portions $250 \mathrm{~m}$ in length (Bianco et al., 2020; Pranzini et al., 2020) and homogenic morphodynamics, as well as lacking anthropic interruptions. All Sea-state parameters and Sub-Unit configurations can be observed in Fig. 2.

\subsection{Diagnostic indicators of coastal resilience}

Territorial change indicators enable the different groups of elements comprising the coastal system to be included and weighted in the assessment of vulnerability. They express relevant values when they highlight these feedbacks, which can be more or less clear depending on the physical context of the site (Garcia Ayllon, 2018a,b). For this reason, a tested index often fails to provide supporting results if applied in different settings. The Index of Social and Morphological Vulnerability

\footnotetext{
${ }^{1}$ In Italian law, maritime concessions are the legal permissions given by the maritime domain authority to each municipality to manage activities with minor impact in coastal areas in their jurisdiction. In turn, the municipalities rent them to private stakeholders that establish economic activities (restaurants, shops, leisure spaces, beach bars, etc.) for a time within these portions of maritime territory. Henceforth, the term "concessions" will be used to refer to these non-permanent economic activities authorized under the concession regime of in the maritime space.
} 

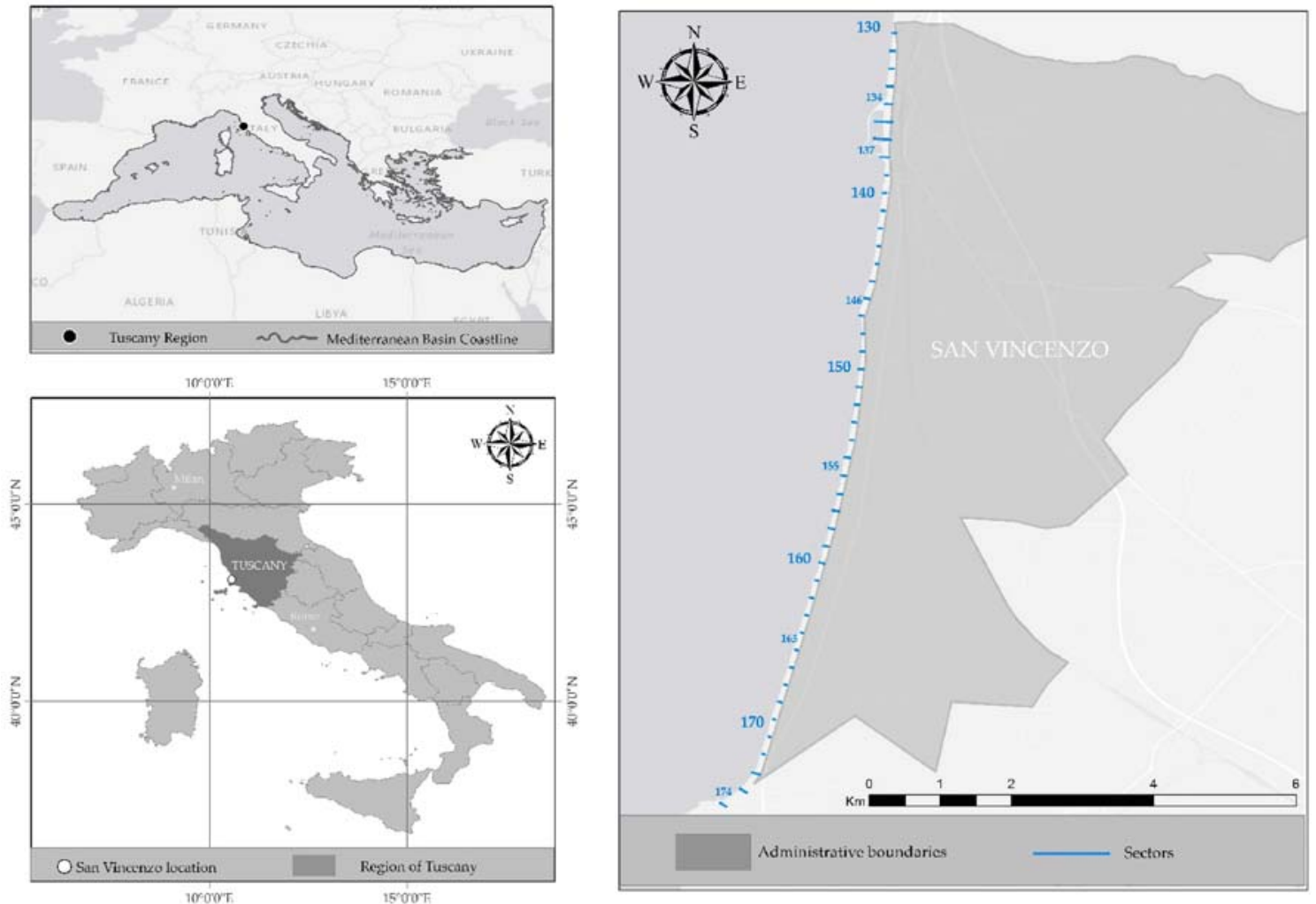

Fig. 1. Test site geographical features.
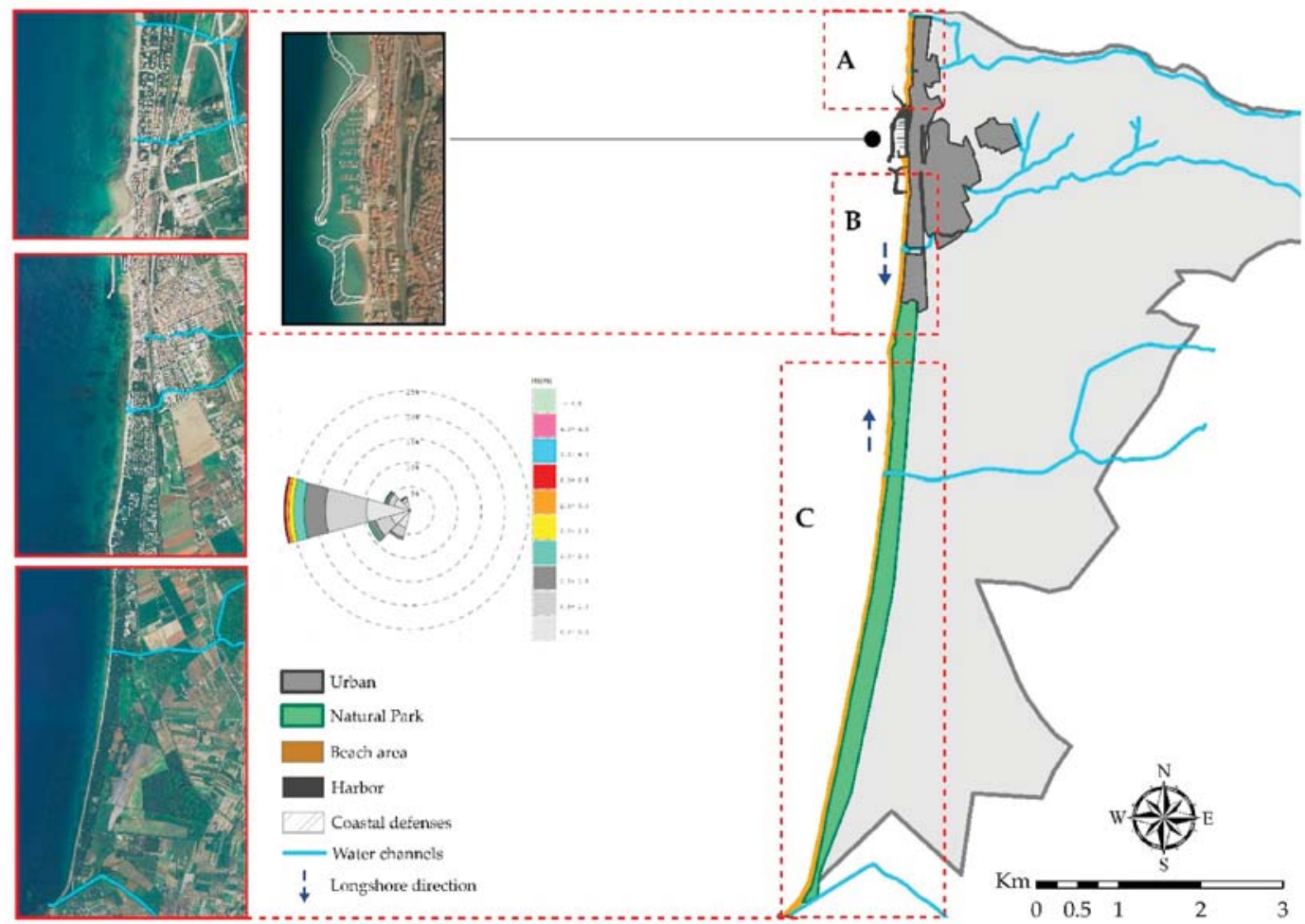

Fig. 2. Partition of the San Vincenzo Unit and main physical attributes; the rose diagram relates with sea state (University of Florence and DEAM, 2007).

(ISMV) proposed was calculated to classify the active beach's vulnerability to coastal erosion, and to investigate the response that the active beach gives to the space reduction. Morphological trends, Economics, and Stressors/Counteractors elements of the area were introduced in the assessment through three respective sub-indices. These sub-indices are the Index of Morphologic Variation (IMV), the Index of Services' Cost 
(ISC), and the Coastal Regeneration Index (CRI). The calculation of these indices comprised the creation of groups of elements considered in the CRI, as well as the conversion of dimensioned morphological trends. These two methodological approaches were integrated to enable dimensionless computing of the diagnostic indicators, as well as to spatialize the data.

\subsubsection{Index of Morphological Variation (IMV)}

The Index of Morphological Variation analyzes the morphological trends of the active beach. These are composed of the shoreline and bathymetric quota displacement. The active beach was defined as the area between the backshore limit and the closure depth, $-7 \mathrm{~m}$ (calculated with a return time period of 50 years, see ). The upper limit of the beach was digitalized using ArcGIS ${ }^{\circledR}$ software by Esri. Aerial images available at the National Geographical Portal (Geoportale Nazionale) relating to the years 1994, 2006, and 2012 were compared together with the Landsat 8 Satellite image from 2019. Through this analysis, hard human-made structures in Sub-Units A and B, and the base of the dunes within Sub-Unit C were mapped. Similarly, two surveys aimed at detecting shoreline and bathymetric displacements were carried out in 2014 and 2018. Shorelines were acquired through GPS-RTK surveys in 2014 and 2018, and then provided as shapefiles. Both the shoreline and the bathymetric features were then georeferenced in WGS84UTM 32N reference system.

To calculate the IMV sub-index, a variation factor was assigned to each of the classes and later used in the calculation at a Sub-Unit scale as follows:

$I M V_{\text {sector }}=V v_{\text {sector }}{ }^{*} L v_{\text {sector }}$

where, $\mathrm{Vv}$ is the Volumetric Variation factor of the seabed, and.

$\mathrm{Lv}$ is the Linear Variation factor of the shoreline for each sector.

$I M V_{\text {Sub unit }}=\sum I M V_{\text {sector }} * Z / \lambda$

where $\mathrm{Z}$ and $\lambda$ are the area of the sector, and of the Sub-Unit considered, expressed in $\mathrm{Km}^{2}$.

Even if a short period was covered by the surveys, it is useful to picture the morphodynamic response of the coastal system to the harbor. The latter was completed in 2014, so the sedimentary stock status at that time represents the conditions to which the beach should revert to after a future traumatic event.

\subsubsection{Index of Services' cost (ISC)}

This sub-index literally considers the price that common users must spend to benefit from the services within the maritime territory. These businesses take advantage of the beach directly, creating accessibility modifications to the maritime domain. A total of 34 concessions cover $41,426.030 \mathrm{~m}^{2}$ of active beach at San Vincenzo. They were analyzed regarding the typology of business, the area they occupy, and the cost of their services. Different sources were considered in order to determine their costs. These values were standardized since rates can vary depending on the tourist operator, owner, or online platform that sells the offers, and of course the type of offer. Two types of businesses exploit the concessions issued by the local municipality:

- Beach establishments: they offer daily, weekly, or monthly rates to rent a beach umbrella, a beach chair, and a beach lounger (or two loungers). This offer does not include the cost of a shower, at an average of $0.5 € /$ shower, nor the cost of further loungers or chairs, and even the use of the toilets.

- Resorts: they own private beaches where the same items that the establishments offer are available with the same period rates, but the requisite to access the beach is to rent a room or an apartment. Resorts represent $65.7 \%$ of the concessions; criteria to individuate the standard offer are the same for the establishments. Hence, a room or apartment (depending on the resort policy and availability) for two people was selected in the options that allowed access to the private beach. All the resorts provided free showers and toilets for their guests. Another variable in the standardization of the offer was the inclusion of room and board. The option which only included breakfast (Bed \& Breakfasts included) was selected, since all the resorts in the area offered it.

Rates were selected from the official structure's booking systems, and where they were demanded from specialized on-line platforms, the most common ones used in Italy were selected, such as Booking (www. booking.com), and Tripadvisor (www.tripadvisor.it). An Appendix "Concessions" is included as an online resource in which their attributes are provided. Prices of the structure's typologies varied depending on the seasons and even on the week of the year. The period of evaluation was chosen through the Tourism Database of the Region of Tuscany (Regione Toscana and ISTAT,2019) filtering data from 2005 to 2018 per year or even parts of the year. Prices of services were studied, and economic classes calculated; a factor was attributed to each of them as with the IMV. The ICS was calculated per each sector first, and later per each Sub-Unit as:

$I S C_{\text {Sub Unit }}=\sum_{n}^{1} I S C_{\text {sector }} / \sum_{n}^{1} \frac{z}{\lambda}$

Where $\mathrm{Z}$ is the considered sector area, $\lambda$ is the considered Sub-Unit area,

$I S C_{\text {sector }}=I C O_{\text {sector }} * I C O_{\text {conc }} * E c$

where Ec is the Economic Class of the sector, attributed as shown below in Table 1.

ICO sector represents the ratio between the surface area occupied by the concession and the total surface of the sector concerned.

ICO conc $=\mathrm{C} / \mathrm{U}$

$\mathcal{C}$ is the area of each concession within the considered sector.

$\cup$ is the area of the sub-unit within which the considered sector is located.

$I C O_{\text {sector }}=\sum\left(I C O_{\text {conc }}\right)_{\text {sector }}$

\subsubsection{Index of Coastal Regeneration (CRI)}

The Index of Coastal Regeneration is calculated to consider Stressors, which support the reducing of space, and Counteractors, which provide or preserve space/sediment. The ratio between the two classes of elements represents the potential of each Sub-Unit to self-regenerate (García-Ayllón, 2017). Water channels, sand dunes, and sand bars mapped in the geomorphological assessment phases were considered as potentially regenerative (Bianco et al., 2020). Stressors were defined as hard defenses, concessions, and buildings within the coastal zone. The latter included private residences and public services such as roads and marinas that border the backshore. All these features were integrated in the ArcMap suite, weighted, and classified. A summary map will be provided with all the features and the resulting indices' distribution in the results. The harbor is not analyzable when calculating the IMV and ISC, and its theoretical regeneration potential could be inferred as 0 ,

Table 1

Economic Classes based on the cost of concession services.

\begin{tabular}{ll}
\hline Economic Class & Values Range $(€ /$ day $)$ \\
\hline 1 & $0-21.5$ \\
2 & $21.5-30$ \\
3 & $30-33$ \\
4 & $33-100$ \\
5 & $100-190$ \\
6 & $190-297$ \\
\hline
\end{tabular}


since restorative elements were totally absent, as well as sedimentary stock.

Using the values assigned to each class, the CRI was calculated as:

$C R I=\frac{R p}{C p}$

where Rp is the sum of Restoring Processes in each sector of the Sub-Unit considered, and.

$\mathrm{Cp}$ is the sum of Stressors in each sector of the Sub-Unit considered.

Parameters to be considered in the CRI sub-index calculation were selected after the coastal stripe analysis. From aerial and satellite images, as well as from field observations, six classes of elements were chosen and associated to some numeric values (Table 2), as happened with other sub-indices.

Counteractors are the geomorphological elements that resulted restorative of the sedimentary stock at the San Vincenzo coastal area (see geomorphological assessment in Bianco et al., 2020). Dunes and submerged sand bars represent the two first classes, to which the values of 2 and 3 were respectively attributed. They offer some natural defenses to the wave action, contrasting cross shore migration of the sediment and even supporting its residence on the emerged beach. A higher value (4) was attributed to rivers and channels since they are the main sources of sediment, excluding the artificial replenishments.

Conversely, stressors were individuated through human-made classes of elements. The first two classes are the economic concessions and the buildings affecting the maritime domain. Weak regulations on the maritime public area may increase the risk of permanent occupation and social injustice. This phenomenon can even facilitate the appearance of buildings in the coastal areas, restricting their use. Hence, a value of 2 was attributed to concessions and 3 to existing buildings. Lastly, the higher value of 4 refers to hard defenses such as coastal infrastructures since they may trigger coastal narrowing and squeezing.

\subsubsection{Index of social and Morphological Vulnerability (ISMV)}

The ISMV is a dimensionless indicator that relates all the sub-indices indicating the degree of relative resilience in the three Sub-Units. It varies depending on both the economic and morphological groups of components of the coastal system, although in the case of concessions, on their density within the unit considered. It was calculated as:

$I S M V_{\text {subunit }}=\frac{\mathrm{U}^{*} C R I}{\pi^{*} I M V^{*} I S C}$

with $\Pi$ being the total area occupied by concessions in the Sub-Unit considered.

From formula (7), the ratio between the total surface area, which is expected to have a known regeneration potential, and the surface area occupied, with its morphological and economic trends, results in the resilience potential of the coast. It also highlights the zero point of the resilience assessment; the elements considered within the resilience assessment define the present day situation, which is therefore the maximum point to which our system could revert to after a future erosive event (Klein et al., 1998, 2011), should the present elements persist.

\subsubsection{Summarized framework of the methodological process}

A workflow diagram to clarify the stages of the study is provided in

\section{Table 2}

(a) Weight attributed to Counteractors elements; (b). Weight attributed to Stressors elements.

\begin{tabular}{llll}
\hline $\mathrm{Rp}$ & Values & $\mathrm{Cp}$ & Values \\
\hline Dunes/Park & 2 & Concessions & 2 \\
Bars & 3 & Buildings & 3 \\
Channels & 4 & Hard defenses & 4 \\
\hline
\end{tabular}

Fig. 3. In short, the model we considered covers the tourist industry and the sedimentary stock of the active beach, as being the space hosting the ecosystem and human activities.

\section{Results}

The Resilience Potential is a singular factor to determine, since a non-univocal procedure exists for its determination, and it is not required by any guidelines in the field of coastal assessment. Two different methods were combined to determine a relative index of resilience potential at a local scale. The model calculates vulnerability classes of morphological changes, and indices of services' price and regeneration of the coast. The results include the ISMV of the three SubUnits analyzed, and a series of sub-indices containing important information for a resolutive strategy.

Morphological patterns were detected ranging from a maximum erosive rate of $-6.5 \mathrm{~m}$ for shoreline displacement, and $-4 \mathrm{~m}$ as bathymetric lowering of the seabed, to a maximum increasing value of $6 \mathrm{~m}$ for shoreline and $2 \mathrm{~m}$ for bathymetry (within the considered timespan), respectively. The maximum values are clearly due to artificial nourishments and hard structures built within the nearest sectors to the harbor. The classes range from a minimum value of 1 , where the shoreline and bathymetric trends are accretionary, to the maximum value of 3 , as high erosive trends of the shoreline and decreases of the seabed's quota (Table 3). Hence the IMV value ranged from 1 to 9.

The sedimentary volume in input and output within every sector's area was calculated for the considered timeframe. This provided shoreline displacement rates that were then divided by the sector's amplitude to obtain average linear variations. The three Linear Variation Classes were determined based on the data observed as shown in Table 3, and a Linear Variation factor was attributed to each sector.

A similar exercise was performed for the bathymetric features. They were detected through two bathymetric measures carried out using both Single Beam as well as Side Scan Sonar technologies. Two Bathymetric Digital Models (BDMs), from 2014 to 2018, respectively, were obtained on the whole length of the submerged beach, and the variation of the quota of the seabed was calculated as the raster difference between the two. The factor is missed in those areas that were not covered by even one of the two BDMs. Table 4 contains the Volumetric Variation Classes and the relative Range Values, while Table 4 reports about the Sub-Unit A case.

The volumetric variations always presented an increase in the seabed of between 0 and $2 \mathrm{~m}$. The only factor $(\mathrm{Vv})$ attributed was 1 , and the IMV was totally dependent from the shoreline displacement. At Sub-Unit A, $50 \%$ of the sectors had a Linear Variation factor (Lv) of 3 in the sectors affected by nourishments and coastal defenses (133 and 134), whilst the remaining $50 \%$ was equally divided between Lv of 1 and 2 . Sub-Unit B had $70 \%$ of its sectors with an Lv factor equal to 1, whilst $10 \%$ had Lv 2 , and $20 \%$ had Lv equal to 3. At Sub-Unit C, 36\% of the sectors had Lv 3, $18 \%$ had Lv 2 and $46 \%$ had Lv 1 . The IMV was calculated for each sector first, and then weighted on the Sub-Unit surface. Its value in the three Sub-Units varied considerably, from just 0.11 in Sub-Unit A, 1.43 in SubUnit B, to a maximum of 1.84 in Sub-Unit C. The higher the value of IMV was, the lower the erosive trend of the Sub-Unit's shoreline was. In SubUnit A, the sectors with the high rates of retreatment (from $-0.75 \mathrm{~m}$ to $-6.5 \mathrm{~m}$ ) represented $50 \%$ of the sectors, whilst in Sub-Unit B this was $20 \%$, and $37 \%$ in Sub-Unit C.

Tables 5 and 6 provide the calculations for Sub-unit A to explain the modalities.

Prices for the third quarter of the year were used to categorize six Economic Classes, (Ec). Those classes ranged from the cheapest $(\mathrm{Ec}=1)$, where the services are provided by beach establishments and cost 21.5 $€ /$ day, to the highest $(\mathrm{Ec}=6)$ where the prices reach the maximum of $297 € /$ day and services are provided by resorts. The Natural Park authorities restrict the normative on the territorial usage to preserve the ecosystem there, and the services they offer are basic and completely 


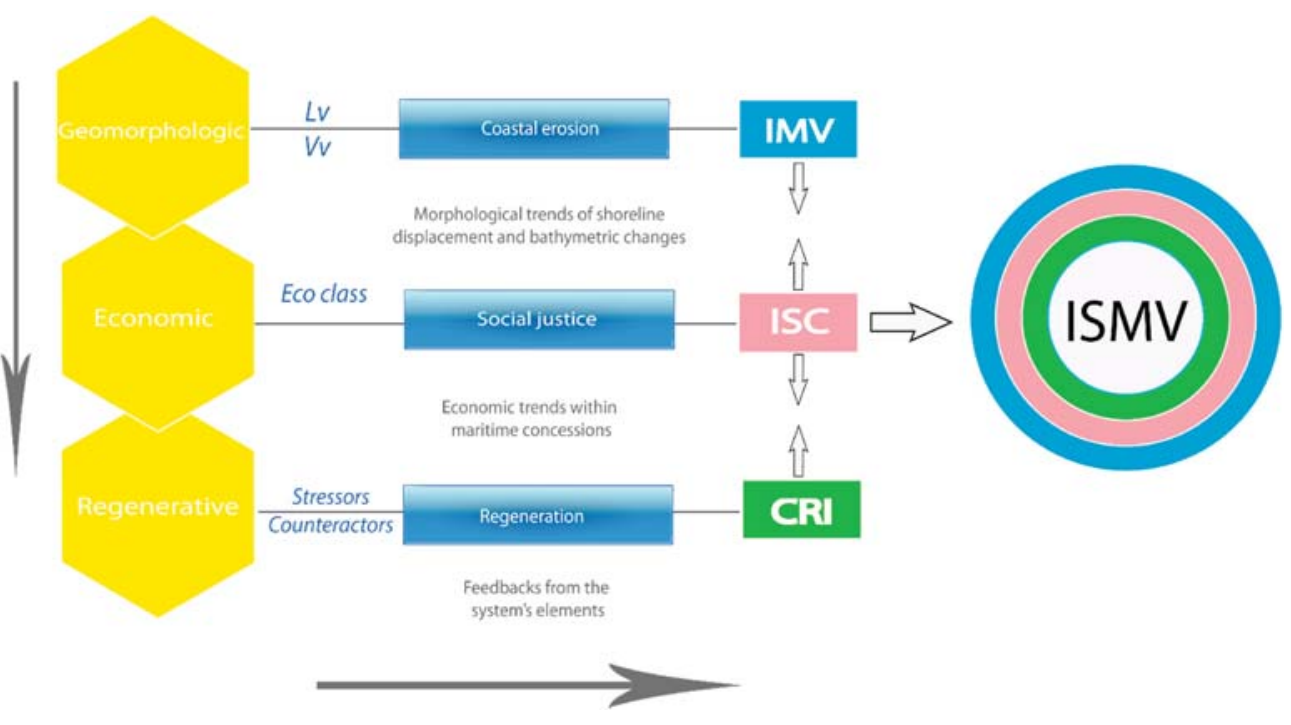

Fig. 3. Workflow summarizing the work phases. Solid arrow on the left side of the diagram indicates the temporal succession of assessments (yellow hexagons); the solid arrow on the bottom reflects the computing process from factors, such as the Linear variation of the shoreline (Lv); Volumetric variation of the submerged beach (Vv); Economic classes (Eco Class); and Stressors/ Counteractors analysis. The third pillar consists of the vulnerabilities determined, while the latter considers the sub-indices calculated to obtain the ISMV. (For interpretation of the references to colour in this figure legend, the reader is referred to the Web version of this article.)

Table 3

Classes of linear variation of the shoreline displacement.

\begin{tabular}{ll}
\hline Linear Variation Classes & Range Values $(\mathrm{m})$ \\
\hline 1 & $6 / 0.05$ \\
2 & $-0.02 / 0.48$ \\
3 & $-0.75 /-6.5$ \\
\hline
\end{tabular}

Table 4

Classes of volumetric variation of the seabed.

\begin{tabular}{ll}
\hline Volumetric Variation Classes & Range Values (m3/year) \\
\hline 1 & $0-2$ \\
2 & $-1-0$ \\
3 & $-4--1$ \\
\hline
\end{tabular}

\section{Table 5}

Linear Variation factor for Sub-Unit A.

\begin{tabular}{llll}
\hline Sub-Unit & Sector & Displacement $(\mathrm{m})$ & Linear Variation factor \\
\hline A & 130 & 1.653135198 & 1 \\
A & 131 & 0.466519006 & 1 \\
A & 132 & -0.328759169 & 2 \\
A & 133 & -4.352153761 & 3 \\
A & 134 & -4.044632219 & 3 \\
\hline
\end{tabular}

Table 6

Volumetric Variation factor for Sub-Unit A.

\begin{tabular}{llll}
\hline $\begin{array}{l}\text { Sub- } \\
\text { Unit }\end{array}$ & Sector & $\begin{array}{l}\text { Lowering/Increasing }\left(\mathrm{m}^{3} /\right. \\
\text { year) }\end{array}$ & $\begin{array}{l}\text { Volumetric Variation } \\
\text { factor }\end{array}$ \\
\hline A & 130 & n.d. & n.d. \\
A & 131 & n.d. & n.d. \\
A & 132 & 0.11 & 1 \\
A & 133 & 0.13 & 1 \\
A & 134 & 0.04 & 1 \\
\hline
\end{tabular}

free. In particular, they provide wooden paths which enable access for mobility impaired users, and the preservation of the dune system, didactics and promotion of the sustainable development of the area. The Ec was considered to be 1 for these sectors.

The ISC Index is high in Sub-Unit B (0.74), low in Sub-Unit A (0.15), and medium in Sub-Unit $C(0.20)$. It is subordinately affected by the density of concessions in the Sub-Unit considered. Within Sub-Unit B,

$50 \%$ of the sectors cover areas with a high price for services (Classes 5 and 6); $72.3 \%$ of them consist of resorts, and in some cases more than $60 \%$ of the sectors' areas are occupied by establishments.

Conversely, Sub-Unit A has the lowest ISC (0.15); this is due to the absence of class 6-concessions, and in just one case, one of the sectors had more than $20 \%$ of its area occupied. These economies are better distributed within Sub-Unit C, and there are no concessions in the last 21 sectors southward. What increases the ISC in this portion is that $100 \%$ of the concessions are resorts. Their price ranged from 213.67 to 249.14 $€ /$ day, with just five such activities occupying an area of $10,935.00 \mathrm{~m}^{2}$. The Index of Coastal Regeneration (CRI) considers the potential of the coast to support human activities. Elements in the Unit were classified as potential supports or contrasts of erosive trends. This depended on the feedbacks that these elements released to coastal dynamics and the sedimentary stock, highlighted in the geomorphological assessment of the area. They were classified and weighted as shown in Table 7, which details how the economic parameters were evaluated and the sub-index ISC was calculated for the analysis of the Sub-Unit A (the smallest of the entire San Vincenzo's coastal stripe).

The calculation method for the ISC was applied for sub-units B and C, and the values compared, in order to obtain a relative classification of the cost of services that take advantage of the active beach at San Vincenzo.

The CRI was 1.21 at Sub-Unit A, 0.01 at Sub-Unit B, and 1.57 at SubUnit C. Particular attention should be paid to the value of 0.01 at SubUnit B. This is the most urbanized portion of the coastal stripe, although the harbor sectors were not included. It hosts $67.6 \%$ of the concessions in the whole San Vincenzo coastal zone. Stressors are largely diffused in the Sub-Unit; buildings are present in the $200 \mathrm{~m}$ distance from the shore in all the sectors, with just two sectors not hosting concessions (sectors 141 and 146). Additional ones are represented by coastal defenses, such as a groin downdrift of the harbor mouth, and the artificial reef mentioned in the first paragraphs of this work. A low CRI was computed for Sub-Unit A, where buildings in the first $200 \mathrm{~m}$ of the backshore were present in all the sectors. In addition, hard defenses have been built in the last sector (134) of Sub-Unit A to contrast the waves reflected from the harbor. In Sub-Unit C, even though coastal defenses are completely absent, the Park is bordered by a main road running N-S. The road is far more than $200 \mathrm{~m}$ from the shoreline in the northern and central part, whilst in the southern one it reduces the coastal zone to less than $200 \mathrm{~m}$. From the other side, sand bars in Sub-Units B and C trap the beach sands within the closure depth -between the isobath $-3 \mathrm{~m}$ and -4 $\mathrm{m}$ - and together with sand dunes increase the CRI. Sand dunes were only diffused at Sub-Unit C and are preserved by the Natural Park Authority 
Table 7

ISC calculation for Sub-Unit A.

\begin{tabular}{|c|c|c|c|c|c|c|c|c|c|c|c|}
\hline Conc_ID & Conc_area (sqm) & $€ /$ day & Class Eco & ICO_conc & Sector ID & Sector area (sqm) & ICO_sect & ISC_sect & $\begin{array}{l}\text { Sub-Unit A } \\
\text { Area (sqm) }\end{array}$ & $\begin{array}{l}\mathrm{ICO}_{-} \\
\text {Sub-Unit A }\end{array}$ & $\begin{array}{l}\text { ISC } \\
\text { Sub-Unit A }\end{array}$ \\
\hline 1 & 945 & 21.43 & 1 & 0.103379031 & 131 & 9141.119 & 0.205314037 & 0.45 & $37,361.955$ & 17.263 & 0.58 \\
\hline 2 & 706.1 & 151.50 & 5 & 0.077244374 & & & & & & & \\
\hline 3 & 225.7 & 170.71 & 5 & 0.024690632 & & & & & & & \\
\hline 4 & 500 & 95.24 & 4 & 0.048344593 & & & & & & & \\
\hline 5 & 200 & 153.00 & 5 & 0.019337837 & 132 & $10,32.418$ & 0.182742561 & 0.09 & & & \\
\hline 6 & 1190 & 172.14 & 5 & 0.115060131 & & & & & & & \\
\hline 7 & 1916 & 21.43 & 1 & 0.178104432 & 133 & $10,757.733$ & 0.178104432 & 0.03 & & & \\
\hline 8 & 766.93 & 21.43 & 1 & 0.107704532 & 134 & 7120.685 & 0.107704532 & 0.01 & & & \\
\hline
\end{tabular}

that limits the use of its territory. Channels flow in all the Units, and although they affect more sectors in Sub-Unit B than in the other SubUnits, the CRI was 0.37 here.

A summary of the results is provided in Table 8, as well as in the comparative plot maps in Fig. 4.

The three values of the ISMV differ greatly among the sub-units. In Sub-Unit B the ISMV is less than 1. Here, all the sub-indices indicated stressing behaviors; both the IMV and the ISC were high, and the restorative dynamics that exist in the Sub-Unit are not balanced with the destabilizing ones acting thereon (the CRI was less than 1). Then, the area occupied by concessions and the high economic class further decreased the ISMV. Obviously, the weights assigned correctly balance the model, highlighting potential erosive feedbacks more than the restoring ones. A similar behavior is acquired by Sub-Unit C, despite having the highest ISMV (4.11). In fact, the CRI was 0.33 in Sub-Unit A, while the ISMV was 1.21 (very close to Sub-Unit C's ISMV). An ISMV greater than 1 tends to have a low ISC, and enough surface area that is not covered by concessions. The IMV affects these rates partially, since none of the bathymetric sectors registered decreases in their seabed's quota.

Sub-Unit A is located updrift with respect to the harbor, consisting of a restricted coastal zone bordered inland by the urban center. It covers a surface area of $37,361.955 \mathrm{~m}^{2}(12.8 \%$ of the total beach area, except the harbor), $17 \%$ of which is occupied by both kinds of concessions (establishments and resorts), with different price classes (from 1 to 5 in Table 1). They result in an ISC index of 0.58 that describes an easily reachable accessible area, where free spaces are available, and the low cost of the services enables access for every kind of guest. Although longshore currents flow North to South, and directly feed this Sub-Unit, the shoreline in the sectors closest to the harbor drastically decreased, so artificial nourishments, and submerged defenses were needed to stabilize it. The IMV was in fact very low (0.11) and depended solely on the shoreline displacement. Nourishments are clearly a palliative action, because the submerged structure did not work as nourished sediment trappings. The Index of Coastal Regeneration (CRI) was the lowest within the whole Unit (0.33). Geomorphological dynamisms in the submerged beach were unable to build positive feedbacks, or even to contrast the erosive trends. The ratio between stressors and counteractors was very low, and the restriction of the coastal zone results in an active coastal narrowing (the average distance between the shoreline and the urban center in the Sub-Unit is $35 \mathrm{~m}$ ). An ISMV of 1.21 was the medium value calculated. The pressurizing elements detailed are clearly

Table 8

Summary of the indices calculated for Sub-Units A, B, and C.

\begin{tabular}{llll}
\hline & Sub-Unit A & Sub-Unit B & Sub-Unit C \\
\hline Area Analyzed $\left(\mathrm{m}^{2}\right)$ & $37,361.955$ & $73,225.420$ & $180,592.812$ \\
IMV: Index of Morphological & 0.11 & 1.43 & 1.84 \\
$\quad$ Variation & & & \\
ISC: Index of Services' Cost & 0.15 & 0.74 & 0.20 \\
$\quad$ CRI: Index of Coastal Regeneration & 0.33 & 0.37 & 4.11 \\
ISMV: Index of Social and & 1.21 & 0.01 & 1.57 \\
$\quad$ Morphological Vulnerability & & & \\
\hline
\end{tabular}

the main causes of the erosive trends, while potentially restorative features have been hardly weakened through the channels' regimentations, and the shoreline anthropized by hard defenses and harbor. The low values of the CRI and IMV indices within the same sub-unit indicate that the ecosystem cannot be used to enhance adaptability, or even to restore or reduce the risk, since space to seaward or inland phenomena does not exist. The only existing source of sediment is represented by the small channels, for which watershed management plans are needed. They were deeply impermeabilized to limit erosive and transport potential, yet did not acquire a critical role, since San Vincenzo is hydrodynamically isolated from the rest of the sedimentary cell.

Sub-Unit B shows critical conditions and a residual resilience potential (ISMV $=0.01$ ). Water channels, sand bars, and part of the ancient dunes system are present. The beach covers a surface area of 73,225.420 $\mathrm{m}^{2}$ ( $25 \%$ of the whole Unit), $32.8 \%$ of which is occupied by concessions, mostly in the form of resorts (74\% of the total concessions in the SubUnit). Prices here are very high and, coupled with the high occupation, push the ISC to the highest value (0.74) within the whole Unit of San Vincenzo. Although hard defenses were built to face the refracted waves from the harbor entrance, the shifting of the erosive phenomena downdrift required the building of the submerged basin that isolated these sectors. The IMV was 1.43 , which represents a medium acceptable value in the anthropized conditions of the test site. Only $20 \%$ of the sectors were classified with a linear variation factor of 3 , and $10 \%$ with factor 2 (see Table 3). Shoreline displacement was high in only two sectors directly affected by the reflected waves, and the resilience potential results were compromised by the ISC and CRI (0.37). The latter is comparable with the CRI of Sub-Unit A, although Sub-Unit B has more counteractors that are deemed to be considerably spoiled. Water channels are evidently inefficient as sediment providers; the submerged defenses are a further weakness which isolated that portion of the coastal zone, as well as the urban center bordering the backshore. Coastal narrowing restricts the coastal zone to an average distance from the shoreline of about $45 \mathrm{~m}$ where the urban center is located; that distance reaches $200 \mathrm{~m}$ where the Sub-Unit is bordered by the Natural Park, as in the southern part. Part of an ancient dune system confers weak stability to the emerged areas there, while some sand bar systems acting between the isobath 3 and $4 \mathrm{~m}$ involve part of the sediments trapped from the shore in longshore drifting. Sustainable designs for Sub-Unit B should afford protection of the upper part through NBS and the planned retreatment of some economic activities that could be shifted to other Sub-Units. In particular, the high cost of the services, together with the high density of concessions, expose the Sub-Unit to a risk of social injustice. Access to the area becomes hard because of both the high prices and the space available for different kinds of users. Most of the concessions are resorts that have an average cost of $183.8 € /$ day, involving hard buildings over-imposed on the coastal zone.

Sub-Unit C obtained the highest values of ISMV (1.57), CRI (4.11) and IMV (1.84), while a very low ISC (0.2) compromised its resilience potential. In particular, the sub-unit covers a surface area of $180,592.812 \mathrm{~m}^{2}$ ( $62 \%$ of the whole Unit), all bordered by the Rimigliano Natural Park. Although establishments occupy just 13\% of the SubUnit's area, all of them belong to resorts. Attention should be paid to the 

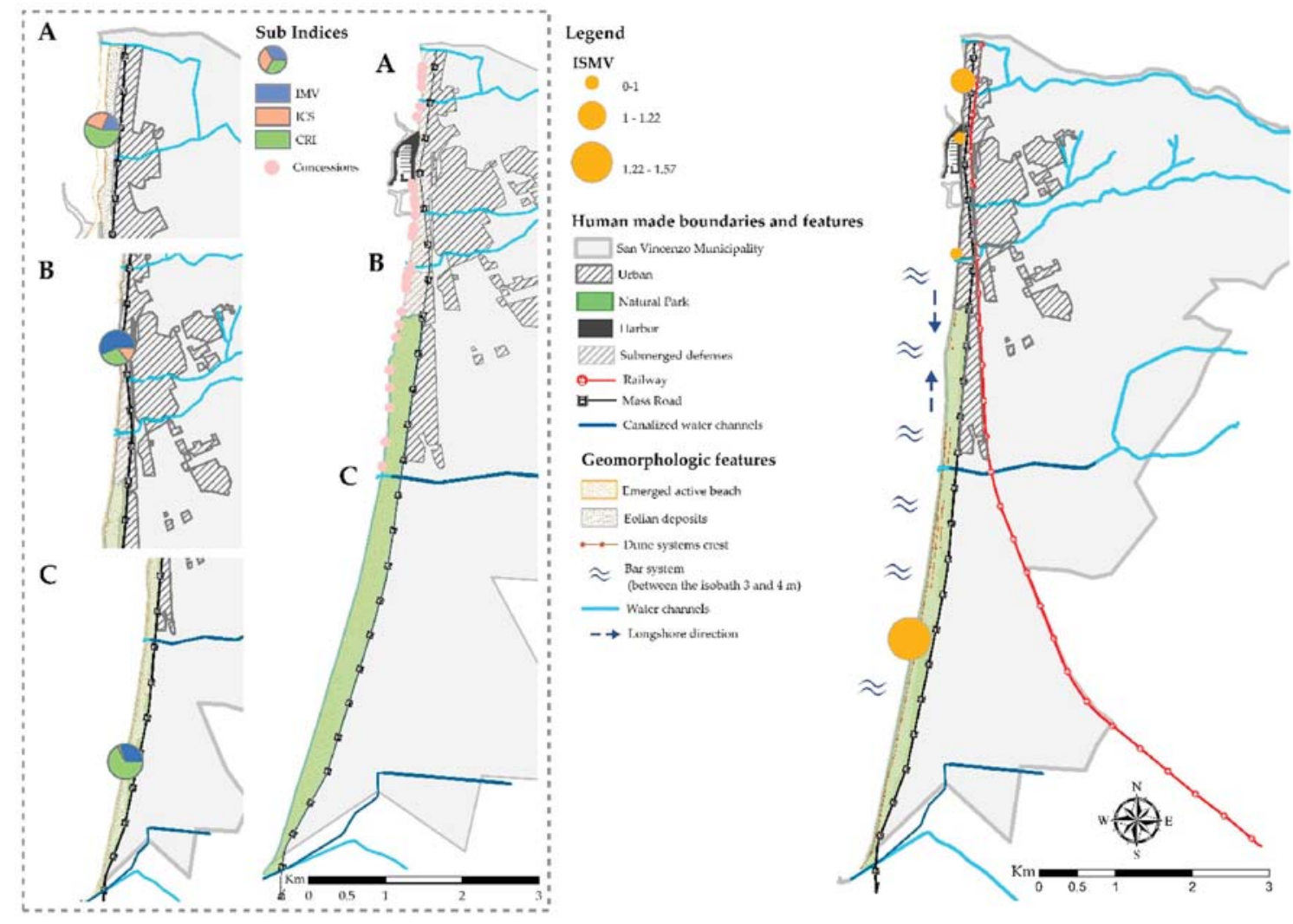

Fig. 4. ISMV Index and the elements considered for its calculation are provided in the large plot map on the right. Small plot maps on the left relate to the Sub-Units (A-B-C).

fact that five concessions occupy a total surface area close to $13,000 \mathrm{~m}^{2}$ within the whole Sub-Unit B, which is the most anthropized, and that 23 concessions cover a surface area of $21,041.3 \mathrm{~m}^{2}$. The prices are the highest in the area (average value of $241.85 € /$ day), and the ISC is notably affected by that. On the other hand, an area of $49,184.120 \mathrm{~m}^{2}$ is totally accessible for free, which would truly increase the ISMV of the whole Unit if we calculated it to a Unit scale. Benefits of the strong rules adopted in the Natural Parks also consist in the low number of concessions, and the inexistence of coastal narrowing phenomena. The backshore here consists of ancient dune systems and reclaimed areas that leave the hard borders at a distance of over $200 \mathrm{~m}$ (except for the southern sectors). Other geomorphological elements that should be preserved are the sand bar systems on the active submerged beach, and the two channels flowing in this Sub-Unit. Even if they have been artificially canalized, their regenerative potential is very high. The ISMV is comparable with that of Sub-Unit A, considering the risk of social injustice (ISC). The Index of Morphological Vulnerability (IMV) is the highest in the Unit; $37 \%$ of the beach sectors had a factor of linear variation of 3 , and $21.4 \%$ of 2 . Within this Sub-Unit, the longshore currents drift inversely (S-N), and the only channel on the southern part is canalized and defended as an internal berthing area for boats.

A graphical comparative approach of the behavior of the indices, and of the most appropriate management strategies they support, are summarized in Fig. 5.

\section{Discussion}

The management of beaches usually follows non-cross-disciplinary technical criteria (Rangel-Buitrago et al., 2020). It is common to decide on the construction of port infrastructures based on environmental parameters of sedimentary dynamics, the actions of regeneration of the sand line based on geomorphological criteria, or the authorization for the implementation of small temporary concessions in maritime public spaces, such as bars or leisure areas, based on socio-economic and urban criteria (Pranzini et al., 2015). The absence of a heterogeneous and multidisciplinary approach makes it difficult to implement issues such as the concept of social justice in public spaces traditionally of high social demand in developing countries such as beaches. In this context, the new mixed approach proposed using multivariate spatial indicators is very interesting when conducting a holistic analysis of the vulnerability and resilience potential of our beaches.

In developed countries with high levels of territorial anthropization on the coast; where beaches are a fragile asset of high economic value, this new approach becomes even more necessary. The current authorization of private uses in the public space of the beaches is usually controversial, but for environmental reasons, rather than for a question of social justice. The long delay in time of cause-effect relationships in coastal phenomena implies that on many occasions criteria of social justice are not properly applied to political decisions when transforming the coastal territory. In Mediterranean countries, it is common to find social controversies in coastal areas about phenomena whose current effects are the consequence of actions carried out in the 1960s, 1970s or 1990s for example.

On the Spanish Mediterranean coast, for example, we can find various cases in this regard. A common controversy usually concerns the north-south imbalances that occur on the beaches as a result of the construction of a marina (Garcia Ayllon, 2018a,b). Apart from the overall economic benefit that said infrastructure produces in the area, this usually produces a tourist damage on the beaches located south of the port that tend to be reduced due to the lack of sedimentary inputs, compared to those in the north that tend to be enlarged (see the impact on the beach line of the construction of the port of San Pedro del Pinatar (Spain), in Fig. 6).

This problem can have relevant social implications if it goes to the extreme of making the beach disappear. A case with strong social consequences is that which occurred at the mouth of the Rio Segura in the 


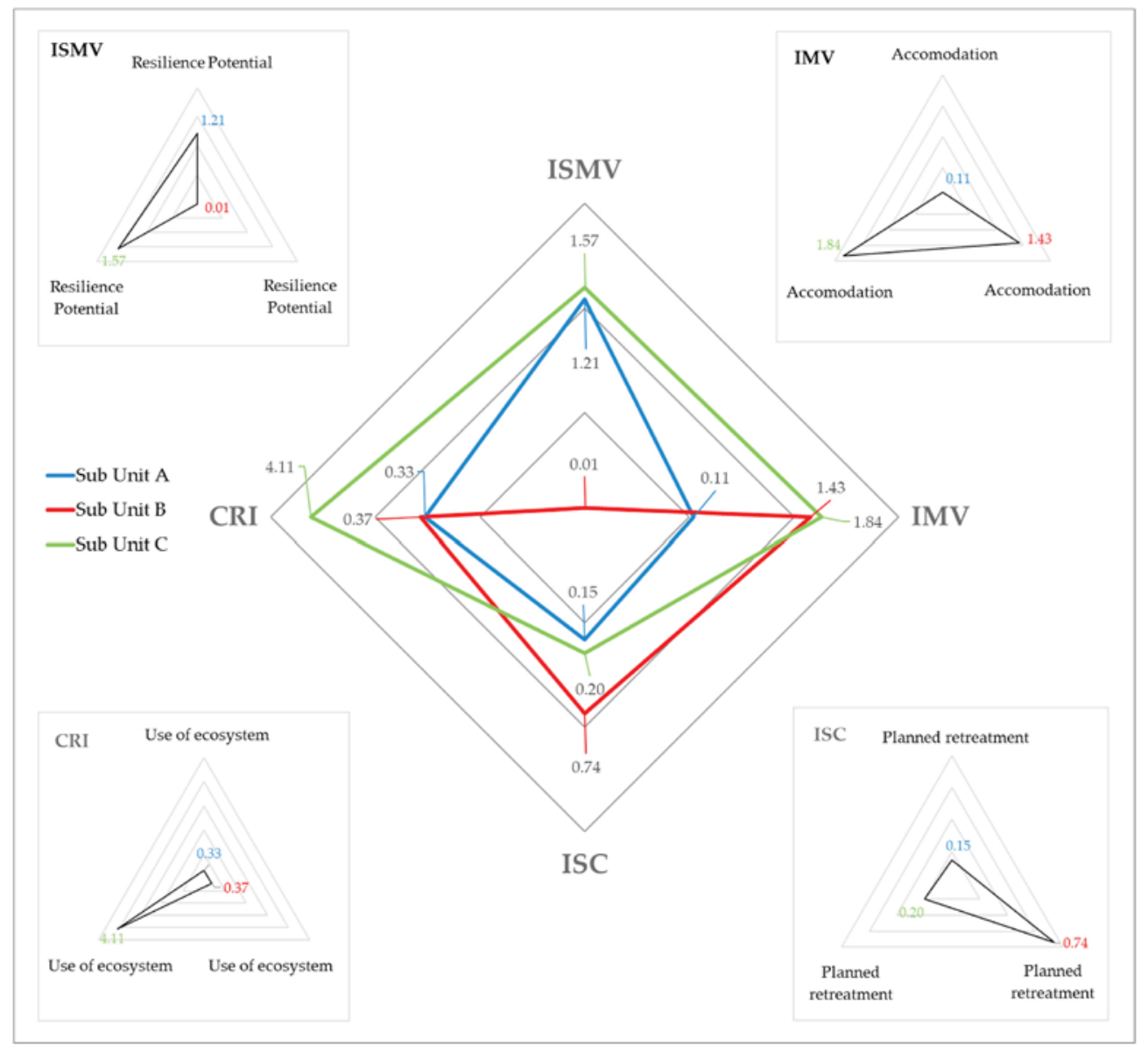

Fig. 5. Comparison between the ISMV and the sub-indices (the weight of each sub indicator in the total ISMV can be inferred for each of the Sub-Units, the sub-plots show the application of each of the most common coastal solutions supported by the indicators).
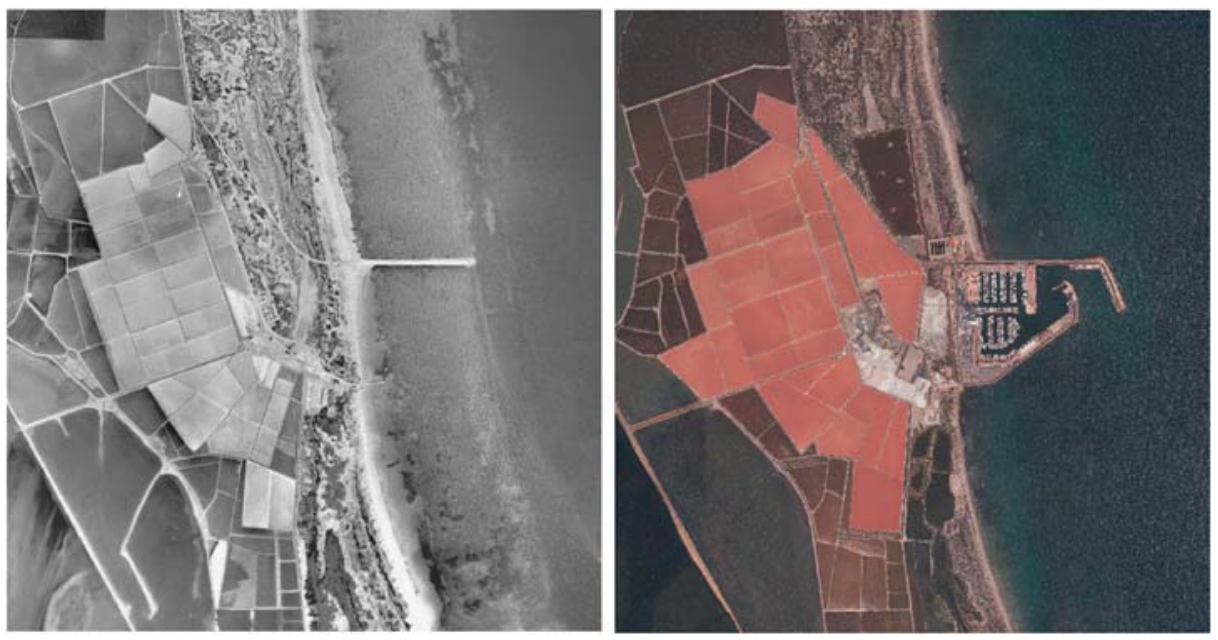

Fig. 6. San Pedro del Pinatar marina's impact on the sand line in south-eastern Spain.

province of Alicante (Spain). The dredging and widening of the mouth in the 1980s, together with the construction of several breakwaters, caused a strong retraction of the beach line to the south (Pagan et al., 2019), leaving many houses built over a hundred years ago exposed to the tide (Fig. 7). However, the time lag of cause-effect relationships, together with the existence of other anthropic phenomena in the area, have made it difficult to carry out an objective diagnosis to settle responsibilities (Pagan et al., 2017). This situation highlights the need to determine the potential for sedimentary resilience in coastal areas such as beaches, beyond geomorphological, but rather social, issues. In this sense, it is quite interesting that the vulnerability of these areas can be parameterized by spatio-temporal indices that help to better understand their behavior from a multidisciplinary approach.

Distinguishing responsibilities and the establishment of actions to restore social justice is even more complex when we find ourselves in heavily anthropized coastal territories. In such a context, a 

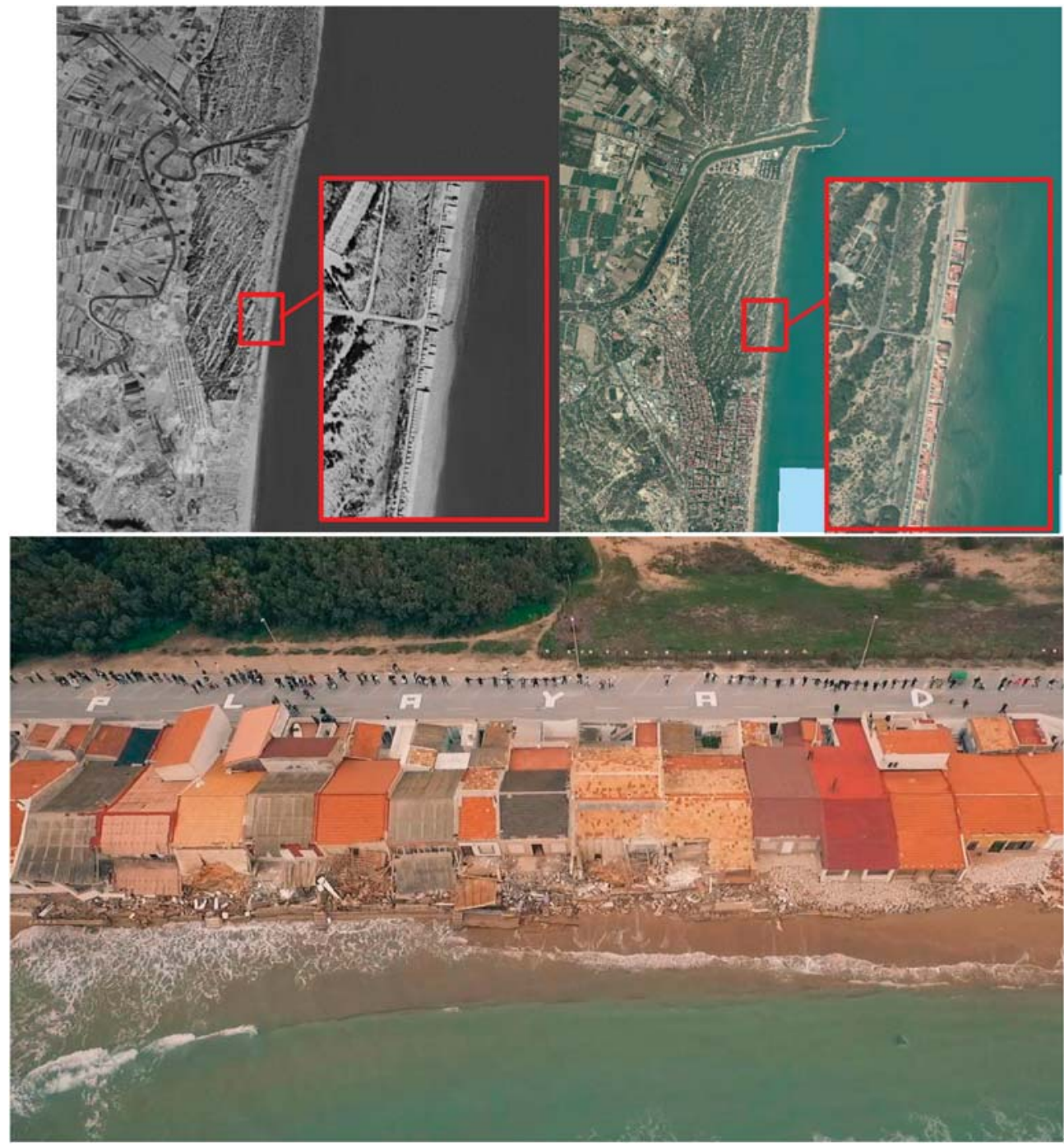

Fig. 7. Transformation of the mouth of the Segura river and the beach line between 1956 and 2019 (above). Neighborhood protests for the destruction of centuriesold houses by waves and storms due to the disappearance of the beach (below). Source: Insituto Geográfico Nacional de España, and Plataforma vecinal Playa Babilonia.

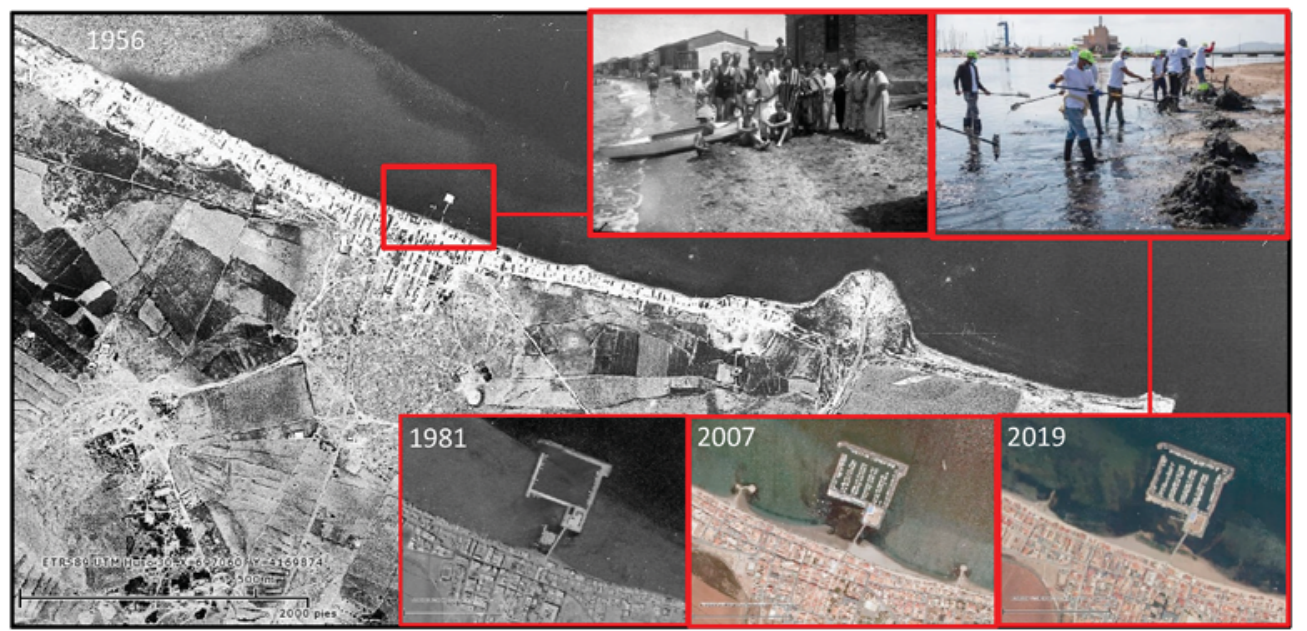

Fig. 8. Los Nietos island harbor's evolution from 1956 to 2019. Source: Sistema de Información Territorial de la Región de Murcia. 
multidisciplinary approach based on multivariate indices for spatial analysis becomes more necessary. An illustrative case of this phenomenon can be found in the towns of the Mar Menor, a coastal lagoon located in the southeast of Spain. For example, the arrival of tourism in the 1970s led to the transformation of Los Nietos, a fishing village with a small beach. Breakwaters were built to increase the beach line, as was an island-type port to shelter leisure boats, without hindering the sedimentary dynamics of the area (Garcia Ayllon, 2018a,b). However, several decades later the result is that the new beach has become a large accumulation of mud that generates protests from all the residents of the town, forcing the authorities to invest in actions to regenerate the beach and withdraw the sludge every year, although there is no clear diagnosis of the problem having been established (Fig. 8).

It has been possible to evaluate all these issues objectively in the case study presented thanks to the use of the proposed new approach. In the specific case of San Vicenzo on the coast of Italy, the ISMV index was calculated for three Sub-Units (A, B, and C) divided on a morphosedimentological base to determine the resilience potential (Bianco et al., 2020). Even though both Sub-Units A and B are bordered by the urban center, only Sub-Unit B presented an ISMV close to zero (0.01). For Sub-Unit A, the ISMV was 1.21, but the highest value was found for Sub-Unit C (bordered by a Natural Park, with 1.57). Although these would results appear logical if related with the presence/absence of urban areas and natural areas, we can observe that the values of Sub-Units A and C were quite similar. The sub-indices that configure ISMV better explained the behavior of the latter and gave indications to adopt and to support resilience. Results from previous studies (Benassai et al., 2015; Ietto et al., 2018) support the conclusions obtained and were considered when setting useable indices for future advances in this matter. They analyzed the risk of exposed values being damaged, or even of citizens being injured. The hazard that arises from the present vulnerability assessment relates with the risk that the sedimentary stock of the active beach (managed at a local level) could be spoiled and not regenerated, and should therefore be integrated within these methodologies.

On the other hand, resilience assessment was also carried out considering approaches from previous studies based on diagnostic indicators (García-Ayllón, 2017; Rumson et al., 2019). The resilience of a coastal area to the anthropic effects of human beings over time can be measured in different ways depending on how these anthropic effects materialize. Different effects that coastal infrastructures such as ports or breakwaters have on the stability of the beach and the configuration of the adjacent shoreline can be easily observed within different Mediterranean areas (see for example Garcia Ayllon, 2018a,b). The indices calculated for this area were indicative of the negative social effects of maritime structures on the bathing water, as well on the shoreline displacement, causing various imbalances in the local sedimentary dynamics. In this sense, the calculated indices are very illustrative of the different vulnerabilities of each of the analyzed sub-units, showing which corrective actions to take in the face of a sedimentary equilibrium more oriented to a criterion of social justice in each of the sectors evaluated.

From the point of view of policy implications in the area of study, numerous studies have been put forward that propose interesting diagnoses and proposals from analyses based on local spatial indicators (see Anfuso and Martínez Del Pozo, 2009 or Ietto et al., 2018). However, all these studies highlighted certain limits. They comprised geomorphological features which are usually missed to properly set the analyzed system, data sources and numerous metrics which are hard to evaluate at a large scale (beyond regional). Such limitations have been partially solved in the present study by restricting the assessment to a local administrative level, where nature-based resolute strategies could be integrated.

Protection defenses could be designed which are nature-based oriented and based on sustainable criteria. Further research into this aspect should be conducted on the beach rock deposits mapped and frequently used as nourishment material (see Bianco et al., 2020). Feedbacks from these kinds of deposits are ambiguous (Calvet et al., 2003; Cooper, 1991; Vousdoukas et al., 2007), and generally the beach rock is exposed where erosive patterns act. Past management plans focused on artificially stabilizing the shore by creating hard borders, with a controlled density of concessions. The surface area could be further utilized to host sustainable and removable businesses. They should serve to maintain the low ISC while respecting the medium to low economic classes.

With respect to the concessions of the maritime territory, they should be relocated at a greater distance, or at least the services' prices should make them more accessible. The processes that could be supported are the ones related to water channels, which here should also be managed at watershed scale, as well as the sand bars that should be preserved to avoid modification of the longitudinal profile of the beach.

Finally, the trends obtained by the indices confirm the geomorphological ones. They highlight the effects of the submerged canyon in the southern sectors, which acts as a trap for the discharged sediment (Bianco et al., 2020). Nonetheless, in the same Sub-Unit the ISMV shows that the ecosystem could be supported to maintain the resilience potential. It could also be increased by reducing the price of the services, or even issuing additional concessions inspired by nature-based solutions for example.

\section{Conclusions}

This research aimed to investigate the resilience potential of sandy beaches in heavily anthropized contexts. A model that integrates vulnerability categorization and territorial diagnostic indicators was applied to a real case study in the San Vincenzo coastal area in Italy. Indicators enabled different groups of elements in the coastal system to be combined, and their feedbacks to be observed in a cause effectoriented analysis. The Index of Social and Morphological Vulnerability (ISMV) constituted the morphological variation of the coastal zone, and the economic data was the price of the services offered at the test site. These economies directly interact with the sedimentary stock since they consist of the establishments and resorts that rent beach spaces during the tourist seasons or even on a permanent basis.

The ISMV index was calculated for three Sub-Units of the study area at beach level. It was found that at unit level, the area affected by a high vulnerability to erosion covered $33 \%$ of the sectors, whilst $19 \%$ had a medium vulnerability, whilst the remaining $48 \%$ ranged between stability and accretion. Through the sub-indices calculated to derive the ISMV the most common coastal solutions were indicated for each of the sub-units. In the areas with high IMV, the continued usage of land at risk could be supported to enable the conservation of the ecosystems. Contrarily, high values of ISC correspond to a relevant risk of accessibility reduction, thus considering the planned retreatment of some concessions as a strategy. Finally, CRI relates with the possibility to support the ecosystem, where the presence of a preserved coastal zone between the coastline and urban areas allows for ecosystem development. The sub-division of the area reflected the coastal dynamic trends, which differ among the three sub-units, as well as singling out two administrative domains of the maritime territory: the municipal authorities and the Natural Parks entity.

\section{Declaration of competing interest}

The authors declare that they have no known competing financial interests or personal relationships that could have appeared to influence the work reported in this paper.

\section{Appendix A. Supplementary data}

Supplementary data associated with this article can be found, in the online version, at https://doi.org/10.1016/j.ecss.2021.107290. 


\section{References}

Anfuso, G., Martínez Del Pozo, J.A., 2009. Assessment of coastal vulnerability through the use of GIS tools in South Sicily (Italy). Environ. Manag. 43, 533-545. https://doi. org/10.1007/s00267-008-9238-8.

Anfuso, G., Martínez-del-Pozo, J.Á., Rangel-Buitrago, N., 2013. Morphological cells in the ragusa littoral (sicily, Italy). J. Coast Conserv. 17, 369-377. https://doi.org/ 10.1007/s11852-013-0233-8.

Barragán, J.M., de Andrés, M., 2015. Analysis and trends of the world's coastal cities and agglomerations. Ocean Coast Manag. 114, 11-20. https://doi.org/10.1016/j. ocecoaman.2015.06.004.

Benassai, G., Di Paola, G., Aucelli, P.P.C., 2015. Coastal risk assessment of a micro-tidal littoral plain in response to sea level rise. Ocean Coast Manag. 104, 22-35. https:// doi.org/10.1016/j.ocecoaman.2014.11.015.

Bhamra, R., Dani, S., Burnard, K., 2011. Resilience: the concept, a literature review and future directions. Int. J. Prod. Res. 49, 5375-5393. https://doi.org/10.1080/ 00207543.2011 .563826

Bianco, F., Conti, P., García-Ayllon, S., Pranzini, E., 2020. An integrated approach to analyze sedimentary stock and coastal erosion in vulnerable areas: resilience assessment of san vicenzo's coast (Italy). Water 12, 805. https://doi.org/10.3390/ w12030805.

Bridges, T., Wagner, P., Burks-Copes, K., Bates, M., Collier, Z., Fischenich, C., Gailani, J., Leuck, L., Piercy, C., Rosati, J., Russo, E., Shafer, D., Suedel, B., Vuxton, E., Wamsley, T., 2015. Use of Natural and Nature-Based Features (NNBF) for Coastal Resilience (Technical Report No. ERDC SR-15-1). US Army Engineer Research and Development Center (ERDC), Washington, DC.

Brown, R.R., Keath, N., Wong, T.H.F., 2009. Urban water management in cities: historical, current and future regimes. Water Sci. Technol. 59, 847-855. https://doi. org/10.2166/wst.2009.029.

Calvet, F., Cabrera, M.C., Carracedo, J.C., Mangas, J., Pérez-Torrado, F.J., Recio, C., Travé, A., 2003. Beachrocks from the island of La palma (canary islands, Spain). Mar. Geol. 197, 75-93. https://doi.org/10.1016/S0025-3227(03)00090-2.

Coastal and Environmental Research Committee, Southeastern Universities Research Association, 2015. Understanding and modeling risk and resilience in complex coastal systems. Presented at the Coastal Resilience Workshop, Washington, D.C.

Comune di San Vincenzo, 2016. Indici demografici aggiornati 2016 [www Document]. Portale istituzionale del Comune di San Vincenzo (LI). accessed 3.24.20. https ://www.comune.san-vincenzo.li.it/pagina208_statistica.html.

Cooper, J.A.G., 1991. Beachrock formation in low latitudes: implications for coastal evolutionary models. Mar. Geol. 98, 145-154. https://doi.org/10.1016/0025-3227 (91)90042-3.

Cooper, J.A.G., McKenna, J., 2008. Social justice in coastal erosion management: the temporal and spatial dimensions. Geoforum, Environ. Economic Geogr. 39, 294-306. https://doi.org/10.1016/j.geoforum.2007.06.007.

Cutter, S.L., Boruff, B.J., Shirley, W.L., 2003. Social vulnerability to environmental hazards*. Soc. Sci. Q. 84, 242-261. https://doi.org/10.1111/1540-6237.8402002.

Cutter, S.L., Webb, J.J., Morath, D., 2009. Social Vulnerability to Climate Variability Hazards: A Review of the Literature. Columbia.

De Girolamo, P., Noli, A., Caputi, P., Visca, C., 2006. Analisi di rischio morfologico e socioeconomico della fascia costiera abruzzese: fattibilità degli interventi di riqualificazione a scala regionale, Regione Abruzzo. Tip.GTE, Fossa (AO).

Doody, J.P., 1992. Sea defence and nature conservation: threat or opportunity. Aquat. Conserv. Mar. Freshw. Ecosyst. 2, 275-283. https://doi.org/10.1002/ aqc.3270020307.

Doody, J.P., 2004. "Coastal squeeze" - an historical perspective. J. Coast Conserv. 10, 129-138. https://doi.org/10.1652/1400-0350(2004)010[0129:CSAHP]2.0.CO;2.

EEA, 2010. Europe's Coasts: Reconciling Development and Conservation [www Document]. European Environment Agency. accessed 1.21.20. https://www.eea.eur opa.eu/highlights/europe2019s-coasts-reconciling-development-and-conservation.

EEA, 2018. Environmental Indicator Report 2018 -In Support to the Monitoring of the Seventh Environment Action Programme [www Document]. accessed 1.21.20). https ://www.eea.europa.eu/publications/environmental-indicator-report-2018.

García-Ayllón, S., 2017. Integrated management in coastal lagoons of highly complexity environments: resilience comparative analysis for three case-studies. Ocean Coast Manag. 143, 16-25. https://doi.org/10.1016/j.ocecoaman.2016.10.007.

Garcia Ayllon, S., 2018a. GIS assessment of mass tourism anthropization in sensitive coastal environments: application to a case study in the mar menor area. Sustainability 10. https://doi.org/10.3390/su10051344.

Garcia Ayllon, S., 2018b. Long-term GIS analysis of seaside impacts associated to infrastructures and urbanization and spatial correlation with coastal vulnerability in a mediterranean area. Water 10. https://doi.org/10.3390/w10111642.

Ietto, F., Cantasano, N., Pellicone, G., 2018. A new coastal erosion risk assessment indicator: application to the calabria tyrrhenian littoral (southern Italy). Environ. Process. 5, 201-223. https://doi.org/10.1007/s40710-018-0295-6.

IPCC, 2007. AR4 Climate Change 2007: Impacts, Adaptation, and Vulnerability [www Document], 1.21.20. https://www.ipcc.ch/report/ar4/wg2/.

Klein, R.J.T., Smit, M.J., Goosen, H., Hulsbergen, C.H., 1998. Resilience and vulnerability: coastal dynamics or Dutch dikes? Geogr. J. 164, 259-268. https://doi. org/10.2307/3060615.

Klein, R.J.T., Nicholls, R.J., Mimura, N., 1999. Coastal adaptation to climate change: can the IPCC technical guidelines be applied? Mitig. Adapt. Strategies Glob. Change 4, 239-252. https://doi.org/10.1023/A:1009681207419.
Klein, R.J.T., Nicholls, R.J., Thomalla, F., 2011. Resilience to natural hazards: how useful is this concept? Global Environmental Change Part B: Environmental Hazards https://doi.org/10.1016/j.hazards.2004.02.001.

Luijendijk, A., Hagenaars, G., Ranasinghe, R., Baart, F., Donchyts, G., Aarninkhof, S., 2018. The state of the world's beaches. Sci. Rep. 8, 1-11. https://doi.org/10.1038/ s41598-018-24630-6.

Martínez, M., Intralawan, A., Vázquez, G., Pérez-Maqueo, O., Sutton, P., 2007. The coasts of our world: ecological, economic and social importance. Ecol. Econ. 63, 254-272. https://doi.org/10.1016/j.ecolecon.2006.10.022.

Mazzanti, R., Pranzini, E., Taccini, S., 1980. Studi di geomorfologia costiera: VII -Variazioni della linea di riva dal Pleistocene medio-superiore ad oggi, caratteristiche sedimentologiche e stato delle associazioni vegetali del litorale di San Vincenzo (Toscana). Boll. Soc. Geol. Ital. 99, 341-364.

McKenna, J., Cooper, A., 2006. Sacred cows in coastal management: the need for a 'cheap and transitory' model. Area 38, 421-431. https://doi.org/10.1111/j.14754762.2006.00708.x.

Ministero dell'Ambiente e della Tutela del Territorio e del Mare, 2017. Le variazioni della linea di costa dal 1960 al 2012.

Neal, W.J., Pilkey, O.H., Cooper, J.A.G., Longo, N.J., 2018. Why coastal regulations fail. Ocean Coast. Manag. SI: MSforCEP 156, 21-34. https://doi.org/10.1016/j. ocecoaman.2017.05.003

Pagán, J.I., López, I., Aragonés, L., Garcia-Barba, J., 2017. The effects of the anthropic actions on the sandy beaches of guardamar del Segura, Spain. Sci. Total Environ. 601- 602, 1364-1377.

Pagán, J.I., Bañón, L., López, I., Bañón, C., Aragonés, L., 2019. Monitoring the dunebeach system of guardamar del Segura (Spain) using UAV, SfM and GIS techniques. Sci. Total Environ. 687, 1034-1045.

Pereira, C., Botero, C.M., Correa, I., Pranzini, E., 2018. Seven good practices for the environmental licensing of coastal interventions: lessons from the Italian, Cuban, Spanish and Colombian regulatory frameworks and insights on coastal processes. Environ. Impact Assess. Rev. 73, 20-30. https://doi.org/10.1016/j. eiar.2018.06.002.

Pontee, N., 2013. Defining coastal squeeze: a discussion. Ocean Coast Manag. 84 204-207. https://doi.org/10.1016/j.ocecoaman.2013.07.010.

Pranzini, E., 1989. A Model for Cuspate Delta Erosion. Presented at the Coastal Zone: Proceedings of the Symposium on Coastal and Ocean Management, pp. 4345-4357.

Pranzini, E., 2018. Shore protection in Italy: from hard to soft engineering and back. Ocean Coast. Manag. SI: MSforCEP 156, 43-57. https://doi.org/10.1016/j. ocecoaman.2017.04.018.

Pranzini, E., Wetzel, L., Williams, A.T., 2015. Aspects of coastal erosion and protection in Europe. J. Coast Conserv. 19, 445-459. https://doi.org/10.1007/s11852-015-03993.

Pranzini, E., Cinelli, I., Cipriani, L.E., Anfuso, G., 2020. An integrated coastal sediment management plan: the example of the Tuscany region (Italy). J. Mar. Sci. Eng. 8, 33. https://doi.org/10.3390/jmse8010033.

Rangel-Buitrago, N., de Jonge, V.N., Neal, W., 2018. How to make integrated coastal erosion management a reality. Ocean Coast. Manag. SI: MSforCEP 156, 290-299. https://doi.org/10.1016/j.ocecoaman.2018.01.027.

Rangel-Buitrago, N., Neal, W.J., de Jonge, V.N., 2020. Risk assessment as tool for coastal erosion management. Ocean Coast Manag. 186, 105099 https://doi.org/10.1016/j. ocecoaman.2020.105099.

Raymond, C.M., Berry, P., Breil, M., Nita, M.R., Kabisch, N., de Bel, M., Enzi, V., Frantzeskaki, N., Geneletti, D., Cardinaletti, M., Lovinger, L., Basnou, C., Monteiro, A., Robrecht, H., Sgrigna, G., Munari, L., Calfapietra, C., 2017. An Impact Evaluation Framework to Support Planning and Evaluation of Nature-Based Solutions Projects. Centre for Ecology \& Hydrology, Wallingford, United Kingdom. Report prepared by the EKLIPSE Expert Working Group on Nature-based Solutions to Promote Climate Resilience in Urban Areas.

Regione Toscana, I.S.T.A.T., 2019. Banca dati turismo -regione Toscana [www Document]. Banca Dati Turismo Regione Toscana. https://web.regione.toscana.it/pe ntaho/api/repos/\%3Apublic\%3ATURISMO\%3ATurismoSaiku.wcdf/generatedConte nt?userid=TURISMORO\&password=LHTe3pem. accessed 3.24.20.

Rumson, A.G., Garcia, A.P., Hallett, S.H., 2019. The role of data within coastal resilience assessments: an East Anglia, UK, case study. Ocean Coast. Manage. https://doi.org/ 10.1016/j.ocecoaman.2019.105004.

Sajjad, M., Li, Y., Tang, Z., Cao, L., Liu, X., 2018. Assessing hazard vulnerability, habitat conservation, and restoration for the enhancement of mainland China's coastal resilience. Earth's Future 6 (3), 326-338. https://doi.org/10.1002/2017EF000676.

Salman, A., Lombardo, S., Doody, P., 2004. Living with Coastal Erosion in Europe: Sediment and Space for Sustainability. Eurosion project reports.

Seto, K.C., Fragkias, M., Güneralp, B., Reilly, M.K., 2011. A meta-analysis of global urban land expansion. PloS One 6, e23777. https://doi.org/10.1371/journal. pone.0023777.

Sterr, H., Klein, R., Reese, S., 2000. Climate change and coastal zones: An overview of the state-of-the-art on regional and local vulnerability assessment (Nota di Lavoro No. 38. 2000). Fondazione Eni Enrico Mattei (FEEM), Milano.

Vousdoukas, M.I., Velegrakis, A.F., Plomaritis, T.A., 2007. Beachrock occurrence, characteristics, formation mechanisms and impacts. Earth Sci. Rev. 85, 23-46. https://doi.org/10.1016/j.earscirev.2007.07.002.

Williams, A.T., Rangel-Buitrago, N., Pranzini, E., Anfuso, G., 2018. The management of coastal erosion. Ocean Coast. Manag. SI: MSforCEP 156, 4-20. https://doi.org/ 10.1016/j.ocecoaman.2017.03.022. 